\title{
REFLEXÕES SOBRE OS JOGOS DIGITAIS SOB A PERSPECTIVA DA SOCIOLOGIA DA INFÂNCIA
}

\author{
REFLECTIONS ON DIGITAL GAMES FROM THE PERSPECTIVE OF \\ SOCIOLOGY OF CHILDHOOD
}
REFLEXIONES SOBRE LOS JUEGOS DIGITALES DESDE LA PERSPECTIVA DE LA SOCIOLOGÍA DE LA INFANCIA

\author{
Rafael Marques de Albuquerque ${ }^{1}$; Caroline Kern ${ }^{2}$
}

\begin{abstract}
RESUMO
Os jogos digitais são objetos relativamente novos na história das infâncias e podem ser compreendidos através de diversos olhares. Neste artigo, levantamos quatro reflexões sobre os jogos digitais e crianças a partir de uma visão alinhada com a sociologia da infância. A primeira diz respeito ao estigma que recai sobre os jogos digitais por sua associação com o universo infantil por meio de uma visão adultocêntrica. A segunda descreve os jogos digitais como molduras para o brincar, consequentemente influenciadoras das formas com as quais as crianças aprendem e se inserem no universo cultural mais amplo. Discutimos, nesse contexto, não apenas as possibilidades dos jogos digitais influenciarem as crianças, mas também de contestarem e reconstruírem seus significados, interagindo ativamente com esses elementos culturais. A terceira problematiza a noção de geração game, destacando a heterogeneidade das gerações. A quarta ressalta a importância dos estudos acadêmicos escutarem mais as vozes das crianças ao se discutir as relações dos jogos digitais com as infâncias. As reflexões do texto têm o objetivo de enriquecer as discussões tanto nos campos de estudo dos jogos digitais quanto no das infâncias, levantando aspectos que merecem ser pensados com mais profundidade e problematizando o papel do adulto nas relações das crianças com os jogos digitais.
\end{abstract}

PALAVRAS-CHAVE: Jogos digitais. Sociologia da infância. Brincar. Criança. Adultocentrismo.

\begin{abstract}
Digital games are considerably new artifacts in the history of childhood and they can be understood from various perspectives. In this article, we reflect on digital games and children from the perspective of the sociology of childhood. The first reflection encompasses the stigma suffered by digital gamers due to the symbolic relation between games and children, mediated by an adultcentric view. The second describes digital games as framing structures for play, consequently influencing the ways children are initiated in their culture. We discuss, thus, not only the potential influences of digital gaming, but also children's possibilities to transgress and construct their own meanings, actively interacting with those cultural artifacts. The third problematizes the notion of 'game generation', highlighting the heterogeneity of each generation. The fourth emphasises the importance of listening to children's voices in academic research when games and childhood are addressed. The reflections aim to enrich the academic discussions, both in the field of digital games and in the field of childhood, raising elements which deserve further and deeper attention and problematizing the role of adults in the relations between children and digital games.
\end{abstract}

KEYWORDS: Digital games. Sociology of Childhood. Playfulness. Child. Adultcentrism.

\footnotetext{
${ }^{1}$ Doutor em Educação - Universidade de Nottingham - Nottingham, Inglaterra. Professor da Escola de Artes, Comunicação e Hospitalidade - Universidade do Vale do Itajaí (UNIVALI) - Itajaí, SC - Brasil. E-mail: albuquerque@univali.br

${ }^{2}$ Doutora em Educação - Universidade Federal de Santa Catarina (UFSC). Florianópolis, SC - Brasil. Professora do curso de Pedagogia - Faculdade Capivari (FUCAP) - Capivari de Baixo, SC - Brasil. E-mail:

Kern.ckern@gmail.com
}

Submetido em: 21/07/2017 - Aceito em: 07/08/2018

(C) ETD-Educação Temática Digital Campinas, SP $\quad$ v.21 n.3 $\quad$ p.662-673 jul./set. 2019 


\section{RESUMEN}

Los juegos digitales son artefactos considerablemente nuevos en la historia de la infancia y pueden entenderse desde varias perspectivas. En este artículo, reflexionamos sobre los juegos digitales y los niños desde la perspectiva de la sociología de la infancia. La primera reflexión abarca el estigma sufrido por los jugadores digitales debido a la relación simbólica entre los juegos y los niños, mediada por una visión centrada en el adulto. El segundo describe los juegos digitales como estructuras de encuadre para el juego, influyendo en consecuencia en las formas en que los niños se inician en su cultura. Discutimos, por lo tanto, no solo las influencias potenciales de los juegos digitales, sino también las posibilidades de los niños de transgredir y construir sus propios significados, interactuando activamente con esos artefactos culturales. El tercero problematiza la noción de "generación de juegos", destacando la heterogeneidad de cada generación. El cuarto enfatiza la importancia de escuchar las voces de los niños en la investigación académica cuando se abordan los juegos y la infancia. Las reflexiones apuntan a enriquecer las discusiones académicas, tanto en el campo de los juegos digitales como en el campo de la infancia, al elevar elementos que merecen una mayor y más profunda atención y problematizar el papel de los adultos en las relaciones entre los niños y los juegos digitales.

PALABRAS CLAVE: Juegos digitales. Sociología de la infancia. Alegría. Niño. Adultcentrismo.

\section{INTRODUÇÃO}

Os jogos digitais se popularizaram nas últimas décadas, fazendo-se presentes não apenas nas casas dos (as) jogadores (as), mas também no imaginário popular sobre a infância. Atualmente, muitas preocupações de cuidadores ou responsáveis pela criação das crianças estão associadas ao jogo digital (ou vídeo game). Algumas dessas preocupações são o excesso de tempo dedicado aos jogos digitais ou o conteúdo potencialmente nocivo desses, como a violência, a sexualização dos corpos e os estereótipos de gênero e etnia (KOWERT e QUANDT, 2016). Provavelmente, a primeira imagem que virá à mente de muitas pessoas quando pensarem em jogos digitais será a de uma criança ou um adolescente jogando. Portanto, é compreensível que, ao refletirmos sobre a infância de hoje, consideremos a presença dos jogos digitais. Essa conexão é importante tanto para entendermos os conceitos de infância que circulam na sociedade nos dias atuais, quanto para pensarmos novos conceitos de infância para um futuro que quase certamente não descartará os jogos digitais.

Nas perspectivas de análise sobre o tema, destacamos neste artigo a sociologia da infância. Sob esse olhar, tentamos questionar ou confrontar uma visão adultocêntrica sobre a criança, que a considera incompleta e inferior, ou seja, mais objeto do que sujeito. Buscamos, também, problematizar e aprofundar as concepções sobre e com a infância. Partimos, para isso, do pressuposto de que as crianças são sujeitos que podem participar ativamente da formulação da cultura, como grupo permanente da sociedade (ABRAMOWICZ, 2011). Propomos, assim, a perspectiva de infância historicizada e compreendemos que as experiências das crianças estão imersas em construtos sociais de infância.

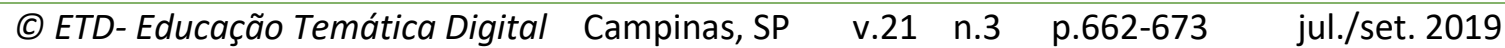


Dessa forma, este artigo apresenta reflexões sobre a intersecção entre estes dois tópicos: os jogos digitais e a sociologia da infância. Nossa tentativa inicial pretende aproximar os dois campos de pesquisa e apresentar reflexões que possam enriquecer a discussão em ambos. Por um lado, contribuindo para os estudos sobre sociologia da infância, ao problematizar a presença dos jogos digitais no cotidiano infantil; por outro, trazendo elementos para que pesquisadores sobre jogos digitais possam refletir acerca do valor de um olhar da sociologia da infância na análise dos jogos digitais como fenômeno social.

\section{ADULTOCENTRISMO E O ESTIGMA SOBRE O JOGAR DIGITAL}

Argumenta-se, neste artigo, como reflexão inicial, que há uma relação entre o estigma social que ainda recai sobre jogadores (as) de jogos digitais e o olhar adultocêntrico. Essa visão subjuga tudo o que é infantil a uma posição de inferioridade.

Para desenvolver este argumento, considera-se necessário primeiro esclarecer que a prática dos jogos digitais não é algo restrito às crianças e adolescentes. Um relatório da Entertainment Software Association (2015) descreveu a idade média dos (as) jogadores (as) estadunidenses como 36 anos. Em outras palavras, os jogos digitais como um todo não constituem uma atividade de crianças, mas uma prática presente em um vasto ramo de faixas etárias, o que inclui crianças. O estereótipo de jogador de jogo digital não condiz, portanto, com o público consumidor. Crianças e adolescentes representam apenas uma parcela. Considerando a média de idade citada, poderíamos até dizer que o jogar digital é uma atividade mais adulta do que infantil. Mesmo assim, no imaginário popular, a associação dos jogos digitais para com crianças e jovens persiste (WILLIANS, YEE e CAPLAN, 2009). Pode-se supor os motivos da continuidade dessa associação entre jogos digitais e infância. A gigante Nintendo, que trabalhava com o mercado de brinquedos e jogos analógicos desde o século XIX, foi uma das principais responsáveis pela recuperação do mercado falido de jogos digitais, no início da década de 1980. Uma de suas estratégias para recuperar a indústria foi posicionar os consoles domésticos como brinquedos. $\mathrm{O}$ uso de uma linguagem visual direcionada para crianças continua sendo uma das marcas da Nintendo até hoje (LUZ, 2010).

Por outro lado, o adultocentrismo manifesta-se, entre outras formas, como uma inferiorização do que é infantil. Associa-se, com frequência, o atributo infantil aos adjetivos de "frívolo, bobo, desimportante, inferior e imaturo". Expressões comuns como "ele é muito infantil" ilustram como o termo, em muitos casos, traz uma conotação negativa nas formas que pensamos e nos expressamos, no senso comum, em relação aos sujeitos dessa faixa etária.

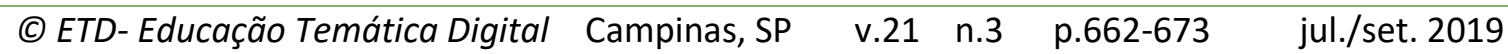


No caso dos jogos digitais, argumentamos que, também em uma visão do senso comum sobre os jogos digitais, esses recebem atributos negativos similares aos que se associam ao universo infantil. Ou seja, é comum que se julgue a prática dos jogos digitais como algo "frívolo, bobo, desimportante, inferior e imaturo". Pouco importa que os jogos digitais sejam mais jogados por adultos (as) do que por crianças, a associação no imaginário popular dos jogos digitais com crianças e adolescentes traz consigo julgamentos inferiorizantes.

É comum que julguemos os jogos digitais como inferiores a outras atividades de lazer e entretenimento. Se, por um lado, o estigma sobre os (as) jogadores (as) parece não ser mais o mesmo que recaía nos anos 1980 e 1990, em que a figura do nerd - termo este que era e ainda é associado com dificuldade de socialização e reputação de "esquisito" - era particularmente estigmatizada, ainda hoje podemos encontrar um julgamento diferenciado para a prática dos jogos digitais. Basta compararmos as avaliações predominantes sobre jogos digitais com as apreciações sobre o entretenimento baseado na televisão e no cinema; sobre esportes; sobre jogos associados ao universo adulto, como os de tabuleiro, cartas, xadrez ou dominó; sobre as artes e a música; ou a outras formas de lazer, como coleção de selos ou jardinagem. Parece-nos que todas as atividades de entretenimento e lazer acima, por serem julgadas como mais pertencentes ao universo simbólico do (a) adulto (a) do que ao infantil, são menos suscetíveis ao ridículo no imaginário popular do que os jogos digitais.

Devemos destacar que não estamos aqui sugerindo a inferioridade do que é fantasioso ou despretensioso. Os ditos universos da infância e o da vida adulta estão repletos de "bobice" e isso não precisa ser visto como algo ruim. Não é uma questão de inferiorizar as atividades de lazer. O problema é a transposição desse tipo de adjetivo com a conotação negativa que ele carrega, de inferioridade, diretamente associado às crianças ou a tudo aquilo que represente a infância. É esse recorte do que se compreende por adultocentrismo que colocamos em jogo. Ou seja, a sobreposição dos (as) adultos (as) e de seus interesses em relação às crianças e às infâncias, a ponto de permitir-se que até mesmo o lazer das crianças - compartilhado ou não por adultos (as) - seja colocado em plano de menor importância.

Pessoas envolvidas com jogos digitais - sejam jogadores (as), designers, vendedores, etc. - podem querer evitar o estigma sobre os jogos digitais através de um descolamento dos desses como algo infantil. Como se os jogos digitais, ao serem julgados como objetos de consumo de adultos (as), estivessem livres desses julgamentos depreciativos. Podemos contrastar esse movimento com o oposto: o de orgulhar-se de ser associado ao infantil, e o de defender que o que é infantil não é menos digno daquilo que é adulto. Essa seria uma maneira de combater o adultocentrismo das formas de pensar a infância. Extrapola-se, assim, a questão de jogo e problematiza-se a própria noção de infância. Mesmo que os dados indiquem que os jogos digitais não são objetos apenas infantis, pode-se transformar o

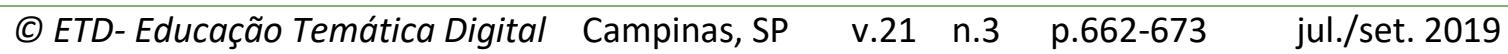


infantil num elogio e não numa associação ao que é indesejado ou vergonhoso.

\section{JOGOS DIGITAIS: NOVAS MOLDURAS PARA A IMAGINAÇÃO}

O brincar possui um papel importante na vida infantil, além de sê-lo também na vida adulta. Conforme as formas de brincar mudam, os modos de "ser criança" também se transformam. Os jogos e o brincar são considerados um espaço de aprendizado, tanto nas versões digitais quanto nos jogos e brincadeiras analógicas. Gee (2007), por exemplo, descreve como brincadeira e aprendizagem mesclam-se nos jogos digitais. Neles, o jogador aprende sobre o jogo, sobre o mundo, sobre si mesmo e sobre o próprio processo de aprendizagem. As brincadeiras tradicionais também são consideradas um espaço de aprendizado. Nesse sentido, Vigotski (2007), embora não possa ser considerado um sociólogo da infância, já levantava questões pertinentes a discussões atuais (como se pode constatar em Sociologia da Infância, cf. CORSARO, 2011). Vigotski (2007) descreve como a criança utiliza-se de sua imaginação para projetar na brincadeira aquilo que ainda não entende ou o que tem dificuldade de lidar sobre sua percepção em relação aos adultos, aprendendo sobre as relações sociais e sobre si nesse processo de constituição humana. Para o autor, ao brincar, a criança aprende a separar objetos da percepção imediata de seus significados e a separar suas ações concretas dos significados que elas têm. Ou seja, o brincar é atividade fundamental na inserção e internalização da criança no universo cultural e simbólico. Em ambos os casos, no brincar digital e no analógico, a criança aprende, experimenta e recria, interagindo com a cultura por meio de instrumentos.

Seria ingênuo ignorar que as ferramentas digitais apresentam novas nuances para a brincadeira e o jogo infantil. Propomos aqui que os jogos digitais trazem uma moldura mais rígida para as possibilidades de aprendizagem do brincar, devido à quantidade de detalhes que no jogo digital tendem a ser mais estabelecidos a priori, se compararmos com jogos analógicos e sua tendência a convidar à imaginação. Não podemos generalizar - alguns jogos digitais podem ser muito convidativos à imaginação, enquanto alguns jogos analógicos podem incentivar uma relação mais pasteurizada. Porém, precisamos reconhecer que os jogos digitais tendem a possibilitar menos espaço para tal. Para aprofundar a questão, precisamos refletir sobre a liberdade da brincadeira. Podemos compreender, como Vigotski (2007), que existem regras, mesmo entre aquelas que parecem mais livres. Para o autor, uma criança que brinca ao imitar um canguru está sujeitando-se a regras autodeterminadas do que pode e do que não pode representar um canguru, numa relação com os conhecimentos que tem sobre o animal. No entanto, mesmo que pensemos em brincadeiras com regras explícitas mais claras, como a amarelinha ou até mesmo o xadrez, argumentamos que os jogos analógicos normalmente são mais flexíveis e adaptáveis. É relativamente fácil para a criança subverter e reinventar o jogo e recriá-lo com suas próprias regras, no xadrez, se analógico. Abramowicz (2011, p. 32) descreve, com base na perspectiva da sociologia da infância, a brincadeira como "a expressão do protagonismo

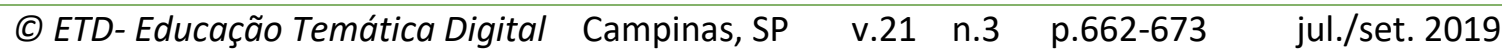


infantil de um exercício da capacidade inventiva da criança". Quanto a essa questão, Finco e Oliveira (2011, p. 72) assim se manifestam:

[...] as crianças pequenas, com seus corpos e com suas espontaneidades, problematizam e questionam esses modelos centrados no adulto, no homem, no branco enquanto categorias molares, mas também se constituindo a partir de movimentos de força contrários a sua iniciação que se faz nas instituições de educação à criança pequena.

Por outro lado, nos jogos digitais, as possibilidades da criança estão mais limitadas ao que foi pré-programado. Podemos ilustrar esse ponto usando novamente o xadrez. Quando analógico, a criança pode negociar com o oponente para que as peças comecem em locais alternativos, ou que a dama deveria poder mover-se saltando por cima de outras peças, como faz o cavalo. Na versão digital do mesmo jogo, isso não é possível. A criança fica presa às regras tradicionais, como uma moldura que amalgama ou engessa suas possibilidades de atuação. Se, na ilustração dada por Vigotski (2007) sobre o faz de conta, um cabo de vassoura pode tornar-se um cavalo, caso a criança queira, nos jogos digitais a tendência é que as interpretações dos objetos sejam mais pré-determinadas, fixas. Se uma criança brincando com uma boneca pode facilmente decidir que na brincadeira ela será uma "super-heroína", uma apresentadora de televisão ou uma astronauta, quando ela joga Rise of the Tomb Raider ${ }^{3}$ (2015) no computador, Lara Croft tenderá a ser, sempre, Lara Croft. É verdade que crianças poderiam imaginar Lara Croft como astronauta, se quisessem e, certamente, as relações simbólicas construídas entre a criança e Lara Croft são variadas, mas nos parece que um tipo de leitura imaginativa é menos encorajada nos jogos digitais do que nos analógicos, de maneira geral.

É verdade que tal generalização provavelmente não serve incondicionalmente. Caso uma criança receba um boneco de astronauta, talvez o boneco seja interpretado sempre como astronauta. Por outro lado, jogos como Minecraft ${ }^{4}$ (MOJANG, 2011) foram projetados de forma a serem bastante imaginativos, sendo que o(a) jogador(a) pode criar suas próprias formas. Salvo o exemplo e sem, por outro lado, querer generalizar afirmando que jogos digitais propõem práticas menos inventivas do que os analógicos, parece-nos ser essa é a tendência geral para a maioria dos jogos disponíveis hoje.

No entanto, não queremos simplesmente atribuir o papel de vilões aos jogos digitais, como tantos fazem. As brincadeiras infantis analógicas continuam coexistindo com e é certo que eles apresentam outras possibilidades aos jovens e crianças, talvez até complementares; são, também, formas de explorar mundos virtuais e fazer com que esses sujeitos se sintam desafiados de inúmeras formas. Em última instância, crianças sempre

\footnotetext{
${ }^{3}$ https://tombraider.square-enix-games.com/

${ }^{4}$ https://minecraft.net
}

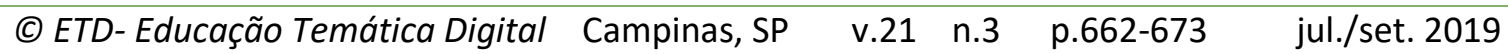


tiveram molduras para seu brincar, molduras essas que são a própria realidade na qual estão inseridas. Seria ingênuo acreditar em uma imaginação pura e intrínseca da criança, sem a influência de seu meio externo. A brincadeira e a imaginação são sempre resultados de sua interação com seu entorno, e os jogos digitais são apenas um novo tipo de ferramenta que se soma às outras. Uma nova ferramenta que, embora rica em alguns aspectos, pode ser menos inventiva e imaginativa do que brinquedos analógicos.

Vamos a um contraponto da visão acima, já que os jogos digitais podem ser utilizados de diversas maneiras. Além daqueles mais imaginativos, como o citado Minecraft, há outras iniciativas ao redor dos jogos digitais. Há ainda a criação artística de fãs, inspirados(as) pelos jogos, chamada de fan art e o texto criativo inspirado pelos jogos, chamado fan fic [abreviação de fiction]. Alguns jogos permitem modding 5 (a modificação pelo jogador de seu sistema de regras) ou a criação de novos mapas. Finalmente, há programas que asseguram aos jogadores(as) também criarem seus próprios jogos ${ }^{6}$.

As possibilidades descritas acima permitem outro olhar sobre o jogar digital e a criança. Nascimento (2011) descreve uma visão da sociologia da infância em que as crianças participam e produzem cultura, tanto com os adultos quanto entre si. Os jogos digitais podem ser também um espaço imaginativo e a interação com adultos pode encorajar este tipo de prática. Se a interação ocorrer de forma muito programada, de acordo com a forma com que o jogo foi projetado originalmente, muitas vezes a prática parece oferecer à criança poucas possibilidades imaginativas. Porém, outras formas de interação podem ir à direção oposta. Algumas iniciativas propõem a criação de espaços escolares nos quais crianças e jovens podem ser encorajados a desenvolver uma relação mais criativa com os jogos, de modo a criar suas próprias narrativas digitais e formas de interação (BUCKINGHAM e BURN, 2007; ALBUQUERQUE e CRUZ, 2013; GARCIA, 2016).

Há ainda perspectivas em que adultos podem mediar a interação das crianças e dos jovens por meio de problematizações críticas do conteúdo dos jogos digitais, como os estereótipos de gênero, etnia e classe social (ALBUQUERQUE, 2014; 2016) para estimular jovens e crianças a terem interpretações mais ativas daquilo que aparece na tela, aparentemente tão pouco convidativo para a reflexão crítica. Tais reflexões tocam em outro ponto envolvendo os jogos digitais e as infâncias, que é o lugar social dos (as) adultos (as) em relação ao jogar digital das crianças. Steinkuehler (2015) discute o quanto cuidadores ou responsáveis por crianças podem sentir-se confusos sobre como lidar com o tema. Segundo

\footnotetext{
${ }^{5}$ Um dos mods mais famosos, que se tornou um sucesso comercial, foi o Counter Strike (lançado originalmente em 1999), uma versão modificada de Half-Life (lançado originalmente em 1998).

${ }^{6}$ Um exemplo de software que permite a criação de jogos de forma amadora é o RPG Maker, publicado originalmente em 1997. Exemplo de aplicação do RPG Maker em contextos pedagógicos podem ser conferidos em Cruz e Albuquerque (2014).
}

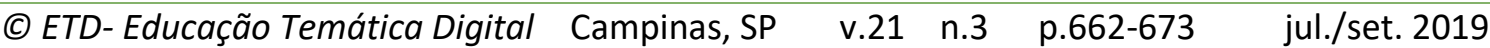


Costa (2010), as tecnologias digitais podem criar uma situação de exclusão dos adultos nos casos em que eles têm menos familiaridade com essas tecnologias do que as crianças, ocasionando-Ihes confusão e insegurança. Muitas vezes, fala-se sobre o importante papel dos (as) adultos(as) em proteger as crianças de conteúdos impróprios para sua idade ou de jogarem excessivamente, mas pouco se discute sobre como os(as) adultos(as) podem participar com as crianças e contribuir para que a prática seja mais imaginativa e rica - em termos cognitivos, culturais e afetivos (ALBUQUERQUE, 2018; ALBUQUERQUE e AINSWORTH, 2018). Nessa linha, alguns autores como Ferreira e Darido (2013) e Albuquerque $(2014 ; 2016)$ sugerem que atividades com jovens e crianças poderiam ajudálos a discutir os potenciais aspectos positivos dos jogos digitais, além dos negativos.

Ao compreender-se os jogos digitais como novas molduras para as formas de crianças e adultos brincarem, também se pode entender essa moldura como possível de ser quebrada ou reinventada pelas próprias crianças e jovens, com ou sem a ajuda de adultos. Uma visão fatalista sobre o fenômeno dos jogos digitais pode ser contrastada com uma leitura desses como um potencial espaço de interação, contestação, transgressão, reinvenção e imaginação. Mesmo porque a reinvenção do brincar é também histórica, como descreve Costa (2010, p. 120), "as transformações e as permanências dos modos de brincar são tributárias das condições sócio-históricas nas diversas temporalidades". Desse modo, a construção de sentidos e práticas com os jogos digitais pode ser percebida como um espaço de disputa e mudança, profundamente entrelaçados com outros fatores sociais, culturais e políticos.

\section{TEMOS QUE FALAR SOBRE A "GERAÇÃO GAME"}

Prensky (2001), em sintonia com outros autores que descrevem novas gerações como gerações tecnológicas, propôs o conceito de geração game. Tal conceito tornou-se relativamente popular na literatura sobre jogos digitais, especialmente nas interfaces com a educação. Posicionando os jogos digitais como um fator central na compreensão de uma geração, esse conceito pode facilmente cair em uma simplificação que é indesejada para a sociologia da infância. A ideia de traçar um perfil cognitivo e emocional de jogadores de jogos digitais e generalizá-lo para todas as gerações recentes é oposta à ideia de que devemos considerar as múltiplas formas de experiências de infâncias, e invisibiliza crianças que estejam à parte desse contexto imaginário de envolvimento intenso com os jogos digitais, seja por dificuldade no acesso, por desinteresse por esses objetos digitais ou quaisquer outros motivos.

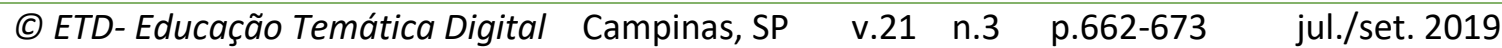




\section{VOZ DAS CRIANÇAS NA PESQUISA SOBRE JOGOS DIGITAIS}

A participação de crianças em pesquisas, em uma perspectiva alinhada com a sociologia da infância, exige a valorização da sua voz. Nesse sentido, as crianças são vistas como sujeitos da pesquisa e não como objetos pesquisados. Para tal, é necessário que as crianças sejam ouvidas e que não se subestime a capacidade delas de expressarem suas visões de mundo, opiniões ou perspectivas. Segundo Abramowicz (2011, p. 21), "pesquisar crianças a partir de sua própria voz se inscreve em uma micropolítica, em uma espécie de movimento político, pois a escola está orientada para a conformação política da criança e é incapaz de escutá-la." Escutar as crianças em vez de minimizar ou subestimar o que elas têm a dizer pode ser incorporado pelas pesquisas sobre jogos digitais. Essa prática não seria uma novidade. Podemos observar desde iniciativas mais tímidas, como por exemplo o estudo de Cruz, Ramos e Albuquerque (2012), até pesquisas que mergulham nas vozes de crianças, como o estudo etnográfico de Stevens, Satwicz e McCarthy (2008). Tais estudos não negam que muitas pesquisas na área dos jogos digitais proponham-se a falar sobre crianças sem necessariamente perguntar a elas o que têm a dizer sobre o assunto em questão. No caso de Albuquerque (2016) escutar os jovens sobre suas relações com os jogos digitais foi tanto um pressuposto ético - por considerar mais respeitoso para com os sujeitos pesquisados que suas visões de mundo sejam expressas e consideradas na discussão sobre o tema, quanto epistemológico, considerarão observar que o envolvimento da voz dos (as) jovens e crianças sobre suas relações com os jogos acrescenta ao valor do conhecimento gerado.

Embora não tenhamos trazido objetivamente a voz das crianças como interlocutoras neste artigo, queremos chamar a atenção para esta possibilidade com base na perspectiva teórica adotada. Considera-se que "as crianças são agentes sociais, ativos, criativos, que produzem suas próprias culturas infantis, enquanto simultaneamente, contribuem para a produção das sociedades adultas" (CORSARO, 2011, p.10).

Ao falarmos de voz, referimo-nos à voz social, ou seja, a voz de um sujeito traz consigo as múltiplas vozes sociais que emanam de suas impressões sobre o mundo, a sociedade, os homens e as mulheres. A voz não é tão somente algo que se faz falando, mas se relaciona com todas as ações que se manifestam nos diferentes grupos sociais. Desse modo, pode-se afirmar que a voz emanada deste escrito reverbera vozes outras, das infâncias vividas e observadas, contudo, com o cuidado de não sobrepor a voz das crianças com a voz de adultos.

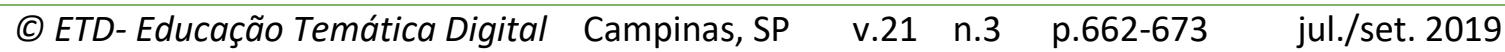




\section{CONSIDERAÇÕES FINAIS}

As reflexões tecidas nestas páginas visam inspirar pesquisadores da área dos jogos digitais a aproximar suas compreensões de infâncias do que consideramos ser um olhar alinhado com a sociologia da infância. Dessa forma, talvez a discussão sobre jogos digitais possa valorizar mais o olhar da criança, como alguém que não consome o jogo digital de forma passiva, mas pode participar como criadora de sua experiência de forma inventiva, transgressora e diversa, apesar do nível de formatação que muitos jogos digitais parecem trazer. Certamente, este artigo não encerra a discussão sobre este tema e sobre esta ótica, mas sugere apontamentos iniciais que podem inspirar investigações e questionamentos futuros.

\section{REFERÊNCIAS}

ABRAMOWICZ, A. A pesquisa com crianças em infâncias e a sociologia da infância. In: GOULART, Ana Lúcia; FINCO, Daniela (Org.) Sociologia da infância no Brasil. Campinas: Autores Associados, 2011. p. 17-36.

ALBUQUERQUE, R. M. Letramento eletrolúdico como conscientização: bases teóricas para educar o jogar. Currículo sem Fronteiras, v. 14, p. 57-74, 2014.

ALBUQUERQUE, R. M. Digital game education: designing interventions to encourage players' informed reflections on their digital gaming practices. 2016. Tese (Doutorado em Educação) - Learning Sciences Research Institute, University of Nottingham, Nottingham (UK), 2016.

ALBUQUERQUE, R. M. Como a curiosidade pode enriquecer o jogar?. In: Daniela Karine Ramos; Dulce Márcia Cruz. (Org.). Jogos digitais em contextos educacionais. Curitiba: CRV, 2018, p. 91-104.

ALBUQUERQUE, R. M.; AINSWORTH, S. Unintentional learning: are digital games friends or foes? In: Rosemary Luckin. (Org.). Enhancing learning and teaching with technology: what the research says. London: Institute of Education Press, 2018, p. 101-109.

ALBUQUERQUE, R. M.; CRUZ, D. M. Letramento digital através de criação de jogos eletrônicos: ensaio comparativo sobre dois contextos escolares. Revista NUPEM (online), v. 5, p. 123-143, 2013.

BUCKINGHAM, D.; BURN, A. Game literacy in theory and practice. Journal of Educational Multimedia and Hypermedia, v. 16, n. 3, p. 323-349, 2007.

COSTA, M. F. V. O brincar em narrativas autobiográficas: um estudo intergeracional. Educação Temática Digital, v. 12, n. esp., p. 107-123, 2010.

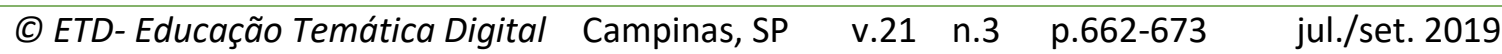


CORSARO, W. A. Sociologia da infância. Porto Alegre: Artmed, 2011.

CRUZ, D. M.; ALBUQUERQUE, R. M. A produção de jogos eletrônicos por crianças: narrativas digitais e o RPG Maker. Comunicação e Educação (USP), v. 19, p. 111, 2014.

CRUZ, D. M.; RAMOS, D. K.; ALBUQUERQUE, R. M. Jogos eletrônicos e aprendizagem: o que as crianças e jovens têm a dizer? Contrapontos (UNIVALI), v. 12, p. 87-96, 2012.

ENTERTAINMENT SOFTWARE ASSOCIATION. 2015 Sales, Demographic and usage data: essential facts about the computer and video game industry. Disponível em: http://www.theesa.com/wp-content/uploads/2015/04/ESA-Essential-Facts-2015.pdf Acesso em: 10 nov. 2016.

FERREIRA, A. F.; DARIDO, S. C. Os jogos eletrônicos no cotidiano dos alunos do $9^{\circ}$ ano do ensino fundamental. Educação Temática Digital, v. 15, n. 3, p. 595-611, 2013.

FINCO, D.; OLIVEIRA, F. A sociologia da pequena infância e a diversidade de gênero e de raça nas instituições de educação infantil. In FARIA, A. L. G.; Finco, D. (Org.) Sociologia da infância no Brasil. Campinas: Autores Associados, 2011. p.55-80.

GARCIA, D. E. S. Letramento em design de games: jogando, criando e compartilhando textos videolúdicos. 2016, 304f. Tese (Doutorado em Letras) - Universidade Católica de Pelotas, Pelotas, RS, 2016.

GEE, J. P. What Games have to teach us about learning and literacy. New York: Palgrave MacMillan, 2007.

KOWERT, R.; QUANDT, T. The video game debate: unravelling the physical, social, and psychological effects of digital games. New York: Routledge, 2016.

LUZ, A. R. Video games história, linguagem e expressão gráfica: do nascimento à consolidação do vídeo game como linguagem. São Paulo: Blucher, 2010.

NASCIMENTO, M. L. P. B. Reconhecimento da sociologia da infância como área de conhecimento e campo de pesquisa: algumas considerações. In: GOULART, Ana Lúcia; FINCO, Daniela (Org.) Sociologia da infância no Brasil. Campinas: Autores Associados, 2011. p. 37-54.

PRENSKY, M. Digital game-based learning. New York: McGraw-Hill, 2001.

STEINKUEHLER, C. Parenting and video games. Journal of Adolescent \& Adult Literacy, v. 59, n. 4, p. 357-361, 2015.

STEVENS, R.; SATWICZ, T.; MCCARTHY, In game, in-room, in world: reconnecting video game play to the rest of kid's lives. In: SALEN, K. (Ed.). The ecology of games: connecting youth, games, and learning. Cambridge: The MIT Press, 2008. p.41-66.

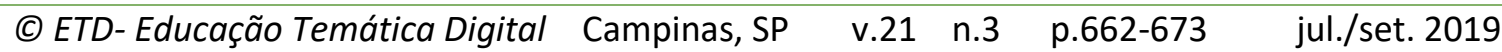


VIGOTSKI, L. S. A formação social da mente: o desenvolvimento dos processos psicológicos superiores. 7. ed. São Paulo: Martins Fontes, 2007.

WILLIANS, D.; YEE, N.; CAPLAN, S. Who plays, how much, and why? A behavioral player census of a virtual world. New Media \& Society, v. 11, n. 5, 2009.

Revisão gramatical sob a responsabilidade de:

Marizete Bortolanza Spezzatto.

E-mail: spessatto.mari@gmail.com

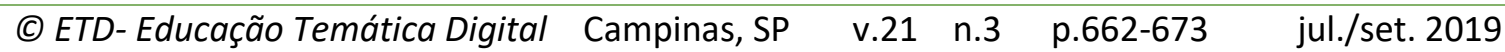

